\title{
Reduced Call Drop Rate in a 4G Network using Vertical Handoff Algorithm
}

\author{
Prachi P. Patil ${ }^{1}$, Urmila Birada ${ }^{2}$ \\ ${ }^{1}$ G. H. Raisoni College of Engineering and Management, Pune, India \\ ${ }^{2}$ Professor, G. H. Raisoni College of Engineering and Management, Pune, India
}

\begin{abstract}
Mobile communication towers are used in many in personal and industrial purposes. It provides a continuous connectivity to a Mobile Nodes (MN) and permits them to change their connection point from current access point to new base station while needed. Handover has become an essential part of mobile communication system because of the limited coverage area of cells. In this paper, investigate the various handover management technologies for providing pure mobility between different access techniques such as GPRS, UMTS, and WI-FI, WiMaX. Vertical handoff refers to a network node changing the type of connectivity it uses to access a supporting infrastructure, usually to support node mobility. Vertical handover can be triggered by various parameters like RSS, bandwidth, packet receiving rate, etc. So in this paper Minimizing delay in vertical handoff to reduced call drop rate in $4 G$ network.
\end{abstract}

Keywords: Vertical Handoff,4G network, Call Drop Rate.

\section{Introduction}

The evolution of $4 \mathrm{G}$ networks will increase the growth in development of a diverse range of high-speed multimedia services, such as at location-based services, mobile entertainment services, e-commerce, and digital multimedia broadcasting. $4 \mathrm{G}$ wireless networks will allows the seamless intersystem roaming across heterogeneous wireless access networks and packet-switched wireless communications [6].

Wireless access technologies have followed different evolutionary paths aimed at unified target: performance and efficiency in high mobile environment. The first generation (1G) has fulfilled the basic mobile voice, while the second generation $(2 \mathrm{G})$ has introduced capacity and overage. This is followed by the third generation $(3 \mathrm{G})$, which has quest for data at higher speed.

\subsection{Literature Survey}

\section{Seminar I survey:}

The evolution of cellular communication system as $1^{\text {st }}$ generation, $2^{\text {nd }}$ generation and 3 rd generation are described. Then GSM, AMPS is explaining briefly then go to the handoff basics and their technique vertical handoff and horizontal handoff. The implementation of vertical handover model depends upon the universal seamless handover architecture [6].

\section{Seminar II survey:}

fourth generation of wireless network is expected to include heterogeneous wireless network that coexist and use a common IP core to offer a diverse range of high data rate multimedia service to end users since the network characteristics that component each other. In that case vertical handoff will remains an essential component for $4 \mathrm{G}$ wireless network due to switching of mobile users amongst heterogeneous network [3][7].

\section{Seminar III and Project Stage I:}

The aim is to provide high data rate services to the users which are in low data rate areas then ad hoc routes are used as high data rate channels. Such a system is called unified cellular and ad hoc network (UCAN) [2]. Another way of using characteristics of cellular and ad hoc network in order to enhance the performance of the cellular system known as converged ad hoc and cellular network system.

This service provider to deliver convenient mobile broadband internet service in more places. Both are open IEEE wireless standards built from the group up for the internet protocol (IP) based application and services. We have to introduce a new combination of WiMaX and Wi-Fi to create a complete a wireless solution for delivery a high speed internet access to business, homes, and Hotspots. This integration is to avoid the disadvantages of each technique by the others and using the advantages optimally. For example, Wi-Fi may over a high data rate (up to $500 \mathrm{Mb} / \mathrm{s}$ )but its power limited due to use of unlicensed band and are there for much more in coverage, while on the other hand even though WiMaX data rate is limited (up to $70 \mathrm{Mb} / \mathrm{S}$ ). it can provide extensive coverage much like the cellular system [4].

This paper introduced a novel method for vertical handoff in 4G wireless heterogeneous networks based on data transfer rate. Log based recovery technique saves the logs in both mobile node and base stations for fast and lossless data recovery.

\subsection{What is mean by Handover}

Handoff is the process of changing the channel (frequency, time slot, spreading code, or combination of them) associated with the current connection while a call is in progress. When a MS moves away from its current AP, it must be reconnected to a new one to continue its operation. The search for a new AP or base station (BS) and following registration without any loss is known as handover following figure 1.2 shows the handoff conversation from base station to other base station. 


\section{International Journal of Science and Research (IJSR) \\ ISSN (Online): 2319-7064}

Index Copernicus Value (2013): 6.14 | Impact Factor (2014): 5.611

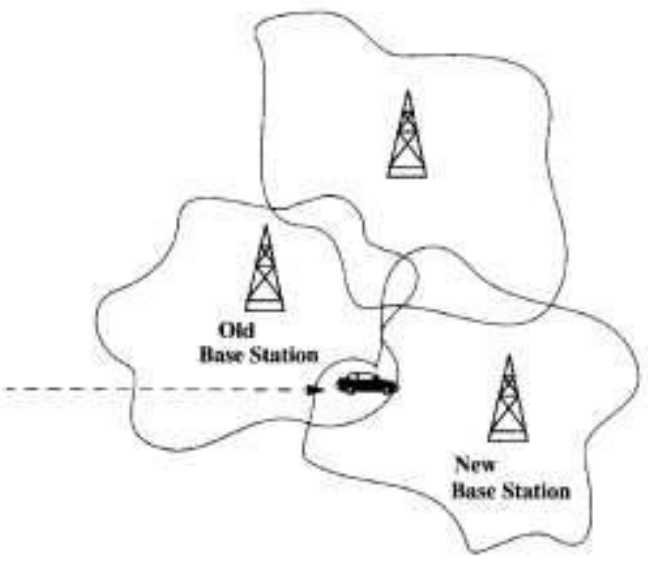

Figure 1.2: Handoff conversation

When a MS moves away from its current AP, it must be reconnected to a new one to continue its operation. The search for a new AP or base station (BS) and following registration without any loss is known as handover and the time required to complete a handover process is known as handover latency. Following Figure shows the scenario of horizontal and vertical handover.

- Horizontal Handover: A mobile node moves with the single network from one AP or BS to the other one is called as," Horizontal handover"e. For Example, mobile node is moving from AP of Wi-Fi network to AP of same network.

- Vertical Handover: A mobile node moves with the different network that is from one BS to the other AP or BS of another network is called as ,"Vertical handovere. Example is AP of Wi-Fi network to BS of Cellular network and vice versa.

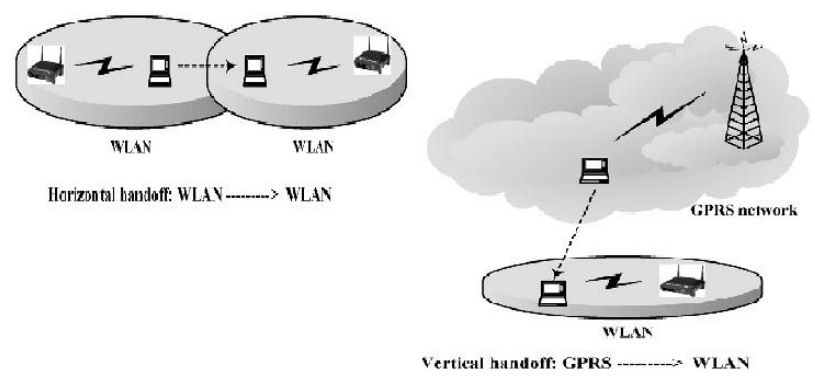

Figure 1.2.1: Horizontal and Vertical handover

Now we will show fourth generation of wireless network is expected to include heterogeneous wireless network that coexist and use a common IP core to offer a diverse range of high data rate multimedia service to end users since the network characteristics that component each other. In that case vertical handoff will remains an essential component for 4G wireless network due to switching of mobile users amongst heterogeneous network. The aim is to provide high data rate services to the users which are in low data rate areas then ad hoc routes are used as high data rate channels. Such a system is called unified cellular and ad hoc network. Another way of using characteristics of cellular and ad hoc network in order to enhance the performance of the cellular system known as converged ad hoc and cellular network system.
4G- The 4G network will consist of internet protocols such as to facilitate the subscribers by enabling the selection of every application and any environment. In $4 \mathrm{G}$ cellular networks high bandwidth with high data rate is required, also in $4 \mathrm{G}$ a quicker and optimized strategy of handover is required to make the clear and reliable communication. The 4Gnetwork system will run with the cooperation of $2 \mathrm{G}$ and $3 \mathrm{G}$ and also will impart IP based wireless communication. The main target in $4 \mathrm{G}$ will be video streaming on IP based protocol, such as IP TV [3]. 4G is one of the upcoming technologies which will support heterogeneous network, many network will be integrated to provide seamless service for wide area to end users. Future $4 \mathrm{G}$ technology aims to provide seamless service across all the networks around the world, support high-speed multimedia services and access to high volume of information including data, pictures, and videos. Some of challenges in $4 \mathrm{G}$ networks we will face that is All-in-one: All-in-one solution means 4G should support any combination of radio access networks. In heterogeneous wireless networks, the mobile devices or mobile terminal will have multiple network interfaces in order to access different wireless networks. Such mobile devices not only support network access and great connection flexibility, but also support mobility between other networks. The ability to achieve wireless access anytime, anywhere and any place has become common expectation as it provides freedom and considerable flexibility in mobility.

Vertical handoff can be triggered by various parameters like RSS, bandwidth, data rate, cost etc. Call drop rate is a big problem in the 4 th generation networks. A vertical handoff based on congestion parameters in the cell is used in a converged ad hoc and cellular network system. This results in less call drop rate.

\section{Related Work}

Fourth generation mobile communication system tend to mean different things to different people, for some it is merely a high capacity new radio interface while for others it is internetworking of cellular. Hand off takes place when a cellular phone user move from the range of one cell to another cell's range and the signal is passed from first base station to the next one. Handover is the process of maintaining user's active sessions when a mobile terminal changes its connection point to the access network (called point of attachment) for example, a base station or an access point. Depending on the access network that each point of attachment belongs to, the handover can be either horizontal or vertical [4].The vertical handoff process can be divided into three main steps namely handoff initiation, handoff decision, and handoff execution.

\section{i) Handoff Initiation Phase}

In order to trigger the handoff event, information to be collected about the network from different layers likes Link Layer, Transport Layer and Application Layer. These layers provide the information such as RSS, bandwidth, link speed, throughput, jitter, cost, power, user preferences and network subscription etc. Based on this information handoff will be initiated in an appropriate time. 


\section{International Journal of Science and Research (IJSR) \\ ISSN (Online): 2319-7064}

Index Copernicus Value (2013): 6.14 | Impact Factor (2014): 5.611

\section{ii) Handoff Decision Phase}

The mobile device decides whether the connection to be continued with current network or to be switched over to another one. The decision may depend on various parameters which have been collected during handoff initiation phase.

\section{iii) Handoff Execution Phase}

Existing connections need to be re-routed to the new network in a seamless manner. This phase also includes the authentication and authorization, and the transfer of user's context information. So, fourth generation of wireless network is expected to include heterogeneous wireless network that coexist and use a common IP core to offer a diverse range of high data rate multimedia service to end users since the network characteristics that component each other. In that case vertical handoff will remains an essential component for $4 \mathrm{G}$ wireless network due to switching of mobile users amongst heterogeneous network.

Handoff can be classified into two types i.e., Horizontal Handoff (Symmetric), which means the handoff within the same wireless access network technology. Vertical Handoff (Asymmetric) means handoff among heterogeneous wireless access network technology. Since VHO is an asymmetric process, the MT (Mobile Terminal) moves between two different networks with different characteristics. So, it is necessary to select the best network which provides high performance. The VHO operation should provide a minimum overhead, authentication of the mobile users and the connection should be maintained to minimize the packet loss and transfer delay.

\section{Existing System}

In the vertical handoffs makes two things clear-

- A vertical handoff brings more delay to the system

- It also causes some calls dropped during the handoff process.

These issues can make interruption to the data services in the converged ad hoc and cellular network system (CACN), so efficient vertical handoff is required [2].

\section{A. Call block probability in cell:}

A fixed spectrum is allotted to a particular cell to a cellular network. So there are limited numbers of channels available to the users. If all channels are occupied at a particular time then the new user is blocked to make a call. There is a probability that call is blocked in such a situation. This Probability is called call blocking probability. Call blocking probability $B$ in a single cell is given by Formula:

$$
B=\frac{(T)^{M} / M !}{\sum_{i=0}^{M}(T)^{i} / i !}=f(T, M)
$$

Where, $\mathrm{T}$ is the traffic density of the cell and $\mathrm{M}$ is the number of cellular band channels.

If an $\mathrm{MH}$ is taking a handoff to $\mathrm{BSi}$, the call blocking probability of BSi can be calculated as:

$$
B_{i}=\frac{(T)^{M} / M !}{\sum_{i=0}^{M}(T)^{i} / i !}=f(T, M)
$$

In order to avoid congesting $\mathrm{BSi}$, an $\mathrm{MH}$ takes a handoff to BSi only when .Bmax is the threshold of call blocking probability and shows the saturated situation of a BS.

\section{Algorithm-1:call blocking probability \\ Input: \\ $\mathrm{T}=$ Traffic density \\ $\mathrm{M}=$ No. of cellular bands in channel.}

\section{Output:}

B-call blocking probability for every cell.

1.Initialize $\mathrm{n}$

$\sum \mathrm{Mi}$ as network cell.

$\mathrm{i}=0$

2.calculate traffic density of cell

sum $=$ sum $+\mathrm{Ti}$;

3.calculate threshold if Bsup $\leq$ Bsub: Bmax

where,

Bsup -previous value

Bsub -present value

4.calculate block Probability

$\mathrm{B}=f(\mathrm{~T} ; \mathrm{M})$

5. Go to step 1 up to $\mathrm{i}=\mathrm{n}$;

\section{B. Transmission drop rate:}

$$
D=\frac{\left(T_{T}\right)^{M_{T}} / M_{T} !}{\sum_{i=0}^{M_{T}}\left(T_{T}\right)^{i} / i !}=f\left(T_{T}, M_{T}\right)
$$

TT defines the traffic density in a TDS and MT shows the number of TDS band channels.

If an $\mathrm{MH}$ is taking a handoff to TDSi, the transmission drop rate of TDSi can be calculated as $D i$

$$
D_{i}=\frac{\left(T_{T}\right)^{M_{T}} / M_{T} !}{\sum_{i=0}^{M_{T}}\left(T_{T}\right)^{i} / i !}=f\left(T_{T}, M_{T}\right)
$$

An MH takes a handoff to TDSi only if . Di $\leq \mathrm{D} \max$. $\mathrm{D}$ max is the threshold value of transmission drop rate,

\section{Transmission Drop Rate.}

1.Initialize

TT -Traffic density in traffic diversion station(TDS) MM-No. of TDS band channel.

2.Define drop rate

$\mathrm{D}=f(\mathrm{Tm}, \mathrm{Mi})$

3.calculate threshold $\mathrm{n}$

If $\sum(D(i)<D(i+1): M a x$ $\mathrm{i}=0$ 


\section{International Journal of Science and Research (IJSR) \\ ISSN (Online): 2319-7064}

Index Copernicus Value (2013): 6.14 | Impact Factor (2014): 5.611

4.go to step 3 upto $i=$ null

Before considering the algorithms remind the below points $\mathrm{TA}=>$ time point of Cell $\mathrm{A}$

$\mathrm{TT}=>$ TDS of cell A

$\mathrm{MA}=>$ overall band channels in A

$\mathrm{MT}=>$ overall band channels in TDS

$\mathrm{N}=>$ overall number of TDS deployed in Cell A.

if the cell $A$ is congested at Ti at time point then

$\mathrm{TE}=>$ extra traffic from neighbor cells

Cell A traffic we can say that $(\mathrm{ti}+1)$ means $(\mathrm{TA}+\mathrm{TE}+\mathrm{TTN})$

then call blocking probability of cell A and transmission drop rate of each TDS ti+1

$\mathrm{Bi}+1=>$ is a call blocking probability

$\mathrm{Di}+1=>$ is dropping rate

\section{Overall call blocking rate}

Bi+1 [overall] $=($ time point of Cell + extra traffic from neighbor cells) * call blocking rate $+(T D S$ of cell * Transmission drop rate of TDS * overall number of TDS deployed in Cell)

I

overall number of TDS deployed in Cell + extra traffic from neighbor cells + TDS of cell *overall number of TDS deployed in Cell

Call dropping rate in saturated condition when it is in vertical handoff

Bi+1 [overall]=time point of Cell * call blocking rate + (TDS of cell + (extra traffic from neighbor cells

/

overall number of TDS deployed in Cell ))* Transmission drop rate of TDS * overall number of TDS deployed in Cell

I

overall number of TDS deployed in Cell + extra traffic from neighbor cells + TDS of cell *overall number of TDS deployed in Cell.

\section{Conclusion and Future Scope}

Simulation results shows the call drop rate and the delay introduced by the vertical handoff should be minimum so research should be oriented towards this topic. The success of $4 \mathrm{G}$ mobile communication will depend upon the new services and contents made available to users. $4 \mathrm{G}$ mobile phone technology promises faster communication Speeds (100 Mbps to 1(Gbps), capacity and diverse usage formats. These new applications must meet user expectations, and give added value over existing offers. After completion of proposed research work we test the whole system. System achieves the maximum packet delivery ratio with minimum call dropping rate. The call drop rate and the delay introduced by the vertical handoff should be minimum so research should be slanting towards this work.

The vertical handover is a very important capability in the future wireless communication era, where an integrated network grouping multiple technologies will try to offer a global broadband access to mobile users.

\section{References}

[1] Madhuri Chennareddy, Dhanaraj Cheelu," A Robust Vertical Handoff Algorithm with Dynamic New Call Blocking Probability for Heterogeneous Wireless Mobile Networks," Research Inventy: International Journal Of Engineering And Science Vol.3, Issue 7(August 2013), PP 13-18

[2] Sunil Kumar, Asst. Professor, ECE Dept., Chitkara University, Baddi, HP, India, "Improved vertical handoff algorithm in a 4G network," International Journal of Engineering Research Technology (IJERT) Vol. 1 Issue 5, July - 2012 ISSN: 2278-0181,

[3] Ram Kumar Singh, AmitAsthana, Akanksha Balyan, ShyamJi Gupta, Pradeep Kumar, "Vertical Handoff in Fourth Generation Wireless Networks," International Journal of Soft Computing and Engineering (IJSCE) ISSN: 2231-2307,Volume-2, Issue-2, May 2012.

[4] Ashish Jain and Anil K. Verma, "Comparative Study of Scheduling AlgorithmsForWiMAX," CSED Department, Thapar University, Patiala, Feb. 2012.

[5] Issaka Hassane Abdul-Aziz, Li Renfa and Zeng Fanzi," HANDOVER NECESSITY ESTIMATION FOR 4G HETEROGENEOUS NETWORKS" International Journal of Information Sciences and Techniques (IJIST) Vol.2, No.1,January ,2012."

[6] Stenio Fernandez, IEEE and Ahmed Karmouch, Member IEEE, "Vertical Mobility Management Architectures in wireless network: A Comprehensive Survey and Future Direction, 2012," IEEE COMMUNICATIONS SURVEYS TUTORIALS, VOL. 14, NO. 1, FIRST QUARTER 2012.

[7] Mithun B Patil ," Vertical Handoff in Future Heterogeneous 4G Network International Journal of Computer Science and Network Security", VOL.11 No.10,October 2011.

[8] Stenio Fernandez, IEEE and Ahmed Karmouch, Member IEEE, "Vertical Mobility Management Architectures in wireless network: A Comprehensive Survey and Future Direction", 2012.

[9] Issak a Hassane Abdul-Aziz, Li Renfa and Zeng Fanzi handover necessity estimation for $4 \mathrm{G}$ network ,International Journal of Information Sciences and Techniques (IJIST) Vol.2, No.1, January 2012. 